九州大学学術情報リポジトリ

Kyushu University Institutional Repository

\title{
High Pressure Torsion of Pure Ti : Effect of Pressure and Strain on Allotropy
}

\section{Edalati, Kaveh}

Department of Materials Science and Engineering, Faculty of Engineering, Kyushu University

Horita, Zenji

Department of Materials Science and Engineering, Faculty of Engineering, Kyushu University

Tanaka, Masaki

Department of Materials Science and Engineering, Faculty of Engineering, Kyushu University

Higashida, Kenji

Department of Materials Science and Engineering, Faculty of Engineering, Kyushu University

http://hdl. handle. net/2324/26390

出版情報: Advanced Materials Research. 89-91, pp.171-176, 2010-01. Trans Tech Publications バージョン：

権利関係: (C) (2010) Trans Tech Publications, Switzerland 


\title{
High Pressure Torsion of Pure Ti: Effect of Pressure and Strain on Allotropy
}

\author{
Kaveh Edalati $^{\mathrm{a}}$, Zenji Horita ${ }^{\mathrm{b}}$, Masaki Tanaka ${ }^{\mathrm{c}}$ and Kenji Higashida ${ }^{\mathrm{d}}$ \\ Department of Materials Science and Engineering, Faculty of Engineering \\ Kyushu University, Fukuoka 819-0395, Japan \\ ${ }^{a}$ kaveh.edalati@zaiko6.zaiko.kyushu-u.ac.jp, ${ }^{b}$ horita@Zaiko0.kyushu-u.ac.jp, \\ 'masaki@zaiko.kyushu-u.ac.jp, ${ }^{\mathrm{d}}$ higasida@zaiko.kyushu-u.ac.jp
}

Keywords: titanium, high pressure torsion, severe plastic deformation, omega phase

\begin{abstract}
High-pressure torsion (HPT) was conducted on commercial grade pure titanium (99.4\%) by applying pressures in a wide range from 1.2 to $40 \mathrm{GPa}$. When the microhardness was plotted against equivalent strain, the hardness saturates to a constant level at each applied pressure. Such a level at the saturation depends on the applied pressure: for up to the pressure of $4 \mathrm{GPa}$, the saturation level is independent of the pressure but, for the pressures above $4 \mathrm{GPa}$, the hardness gradually increases with pressure because of the formation of an $\omega$ phase. Bending tests showed that an excellent ductility as well as high bending strength was achieved for the sample processed at $2 \mathrm{GPa}$. The bending ductility was reduced for the sample at $6 \mathrm{GPa}$ because of the $\omega$ phase formation.
\end{abstract}

\section{Introduction}

Severe plastic deformation (SPD) is an efficient process for the enhancement of mechanical properties through significant grain refinement. There have been many research reports on the application of severe plastic deformation to $\mathrm{Ti}$ and its alloys because of their biomedical use [1,2]. High-pressure torsion (HPT) is a typical process of SPD [3]. An unique feature of the HPT process is the straining under high pressure and this provides oportunities for grain refinement of less ductile materials [4,5], for production of finer grains than the other SPD processes [6] and most interestingly for possible phase transformation [7-9].

In the present investigation, commercial grade pure $\mathrm{Ti}$ is processed by HPT covering a wide range of pressures from 1.2 to $40 \mathrm{GPa}$. The behavior of phase transforamtion from $\alpha$ phase to $\omega$ phase is then examined with respect to imposed strain and applied pressure. Strength and ductility are evaluated by conducting bending tests.

\section{Experimental procedures}

Commercial grade $\mathrm{Ti}$ rods having impurities of $0.013 \mathrm{H}, 0.20 \mathrm{O}, 0.05 \mathrm{~N}$ and $0.25 \mathrm{Fe}$ in mass $\%$ were annealed for 1 hour at $1073 \mathrm{~K}$ under an argon atmosphere. They were sliced to discs with a thickness of $0.85 \mathrm{~mm}$ and diameters of 4 or $10 \mathrm{~mm}$. HPT was carried out on the annealed discs under a selected pressure in the range of 1.2-40 GPa with different numbers of revolutions. It should be noted that the applied pressures in this study were estimated by dividing the loads by the area of the 4 or $10 \mathrm{~mm}$ diameter hole made on the anvils

The facility for the HPT process is illustrated in Fig.1. A thin disc sample is constrained between two anvils under a high pressure and processed by simple shear between two anvils that rotate with respect to each other [6].

The disc samples subjected to HPT were evaluated by (1) Vickers microhardness measurement using a load of $200 \mathrm{~g}$ for $15 \mathrm{~s}$, (3) X-ray diffraction analysis using the Co Ka radiation, (3) microstructural examination using transmission electron microscopy (TEM) and (4) bending tests at a constant cross-head speed. For bending tests, miniature rods with a $0.5 \mathrm{~mm}$ square cross section and 
$9 \mathrm{~mm}$ length were cut from the $10 \mathrm{~mm}$ diameter discs at $1.5 \mathrm{~mm}$ away from the disc center. Each miniature rod was polished mechanically before testing. Three-point bending tests were carried out at room temperature to measure the bending load and displacement. The supporting span was $8 \mathrm{~mm}$ and the stroke was controlled at a cross-head speed of $0.5 \mathrm{~mm} / \mathrm{s}$. The bending stress was caluclated from the load and the specimen geometry through the following equation:

$$
\sigma=\frac{3 P l}{2 b h^{2}}
$$

where $P$ is the bending load, $l$ is the suporting span $(8 \mathrm{~mm}), b$ is the bending specimen width $(0.5 \mathrm{~mm})$ and $h$ is the bending specimen height $(0.5 \mathrm{~mm})$. Due to the limited displacement for the deflection measurement, the bending specimens were further bent manually after removing from the testing machine to check the ductility.

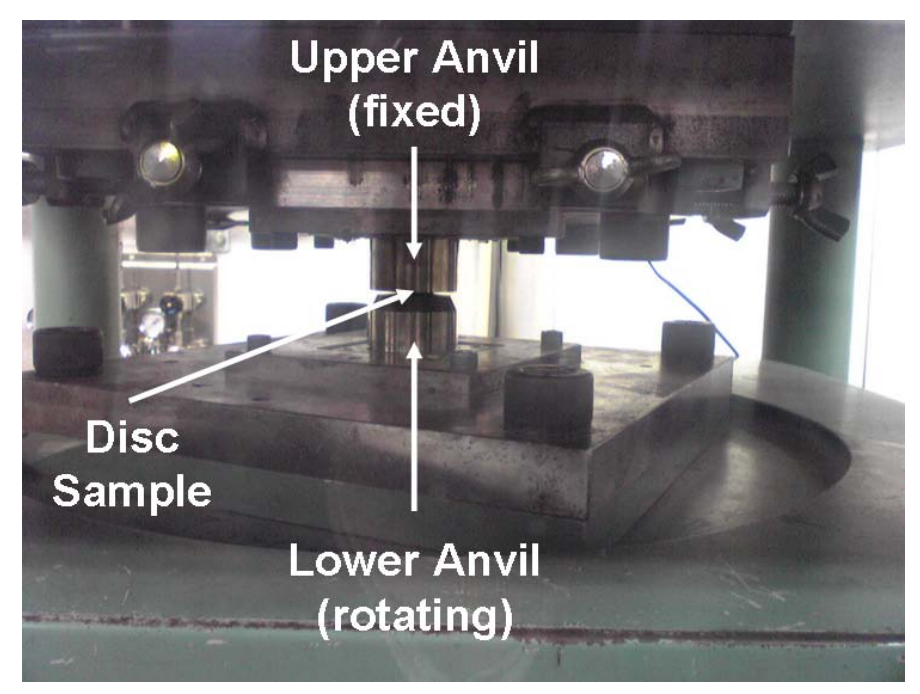

Fig. 1 Appearance of HPT facility.

\section{Results and Discussion}

Figure 2 shows the microhardness variation with (a) the distance from the disc center and (b) the equivalent strain for samples processed after $1 / 2$ to 10 revolutions under the pressure of $1.2 \mathrm{GPa}$. Hardness increases with increasing number of revolutions, increasing distance from the disc center and increasing equivalent strain at early stages of straining. With further strining, the hardness saturates to a constant level where the hardness remains unchanged with straining. This behavior is essentially consistent with the behavior observed in pure Fe [10] and pure $\mathrm{Cu}$ [11]. The hardness at the saturation level is plotted against the pressure in Fig. 3. The saturation hardness is almost constant for the pressures up to $4 \mathrm{GPa}$ but increases with a further increase in the pressure.

A TEM micrograph is shown in Fig. 4 for the sample processed for 10 revolutions under a pressure of $6 \mathrm{GPa}$. The sample corresponds to the state in the saturation level. The microstructures consist of grains with the average size of $\sim 150 \mathrm{~nm}$. It appears that they contain strain associated with dislocations and they are surrounded by boundaries of high misorientations.

The increase in the saturation hardness for the pressures higher than 4 GPa shown in Fig.3 can be attributed to an $\alpha \rightarrow \omega$ phase transformation [12,13]. The evidence for this phase transformation is clearly provided from the XRD profiles as shown in Fig. 5 . The peaks corresponding to the $\omega$ phase can be seen at pressures higher than $4 \mathrm{GPa}$. The fraction of the $\omega$ phase increases with increasing the pressure. These observations are in good agreement with the hardness variation against the pressure shown in Fig. 3. 

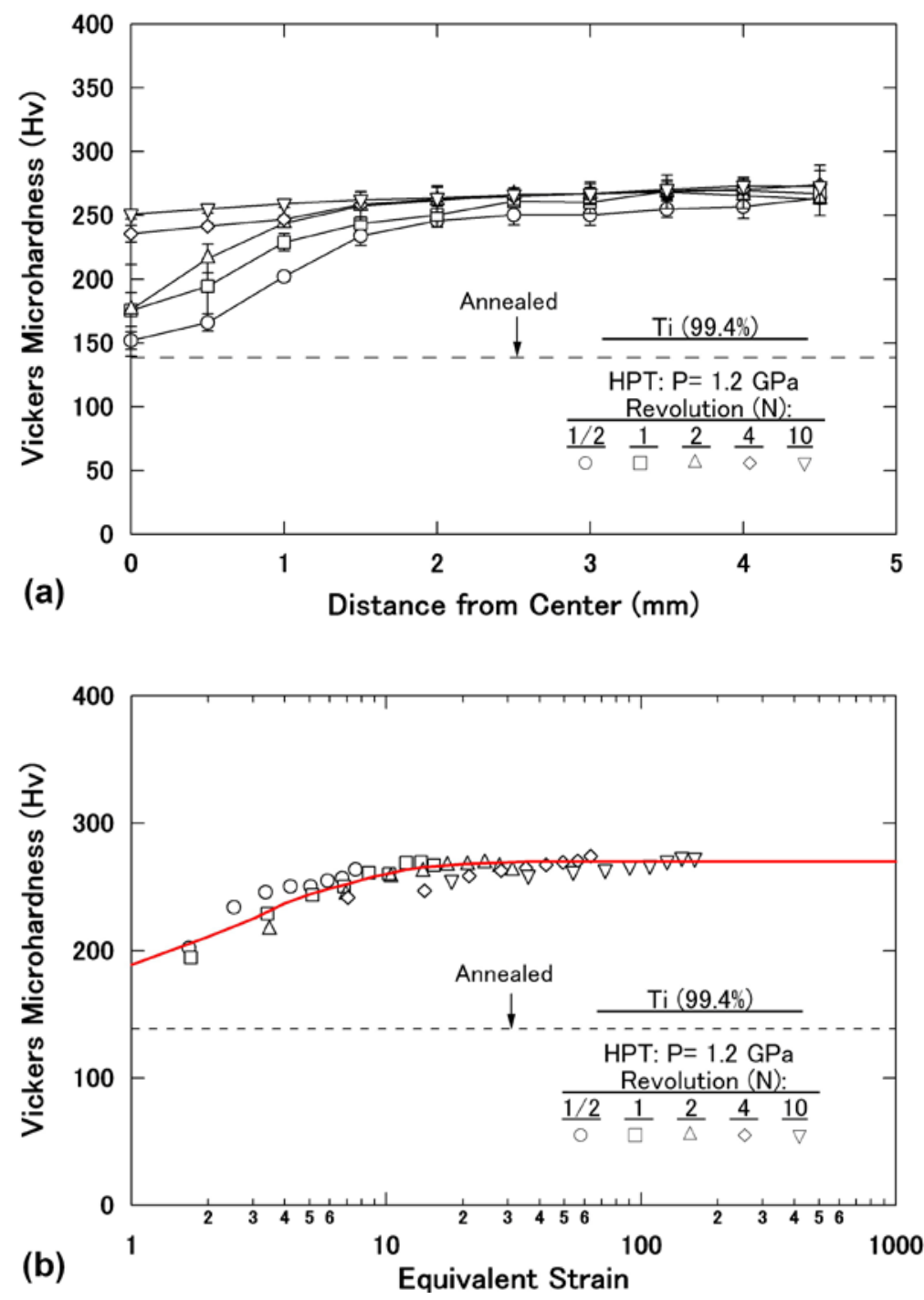

Fig. 2 Vickers microhardness plotted against (a) distance from center and (b) equivalent strain for samples processed under pressure of 1.2 GPa after various revolutions.

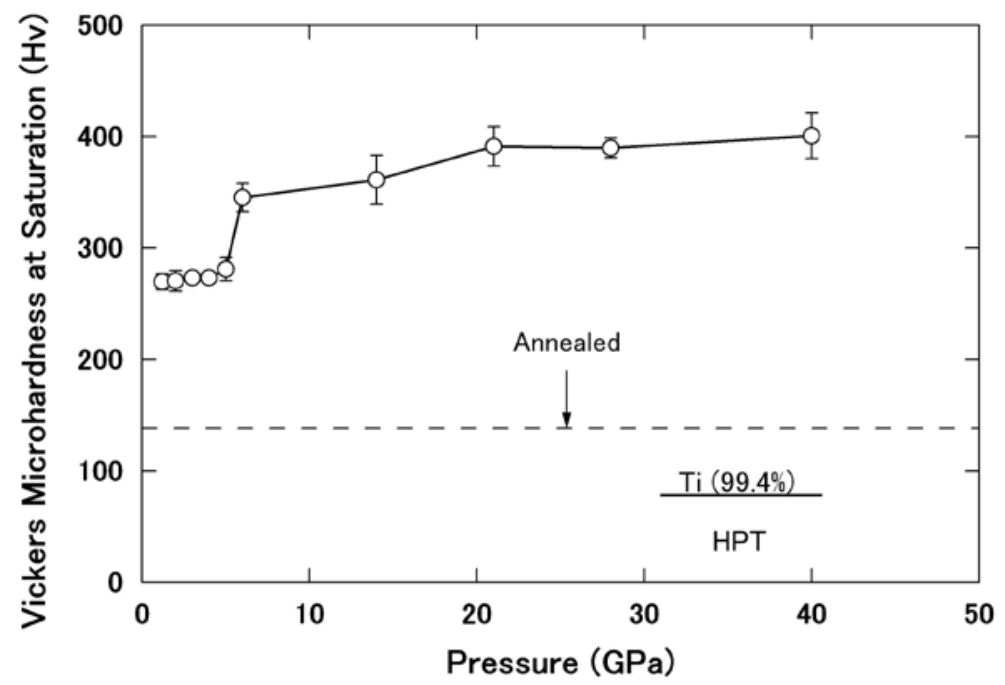

Fig. 3 Saturation Vickers microhardness plotted against pressure. 


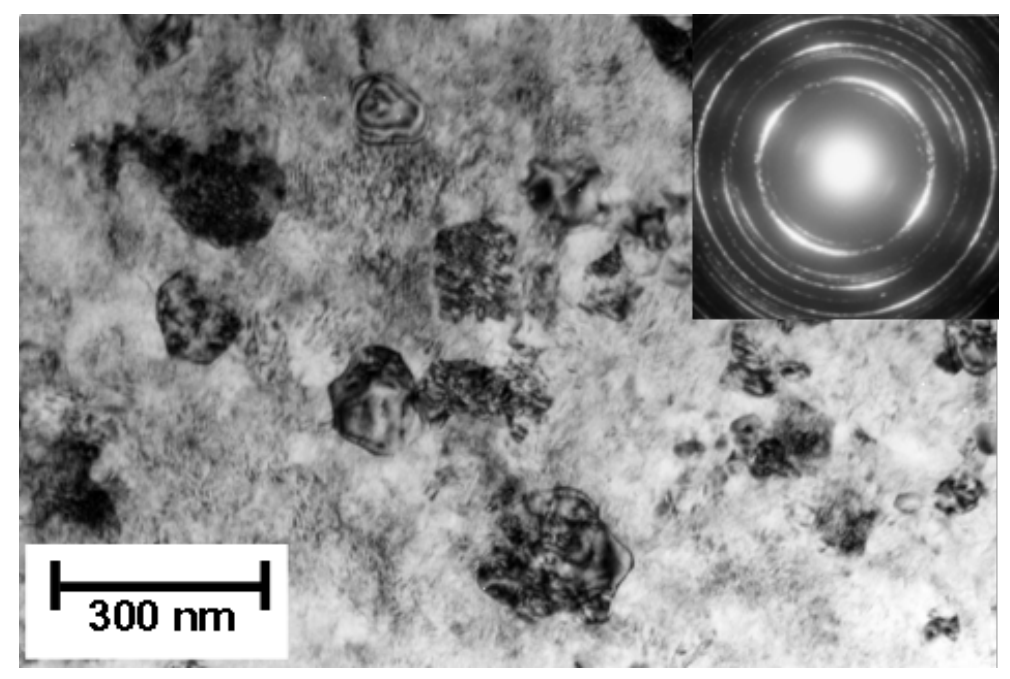

Fig. 4 TEM bright-field micrograph and SAED pattern for sample processed at 6GPa after 10 revolutions.

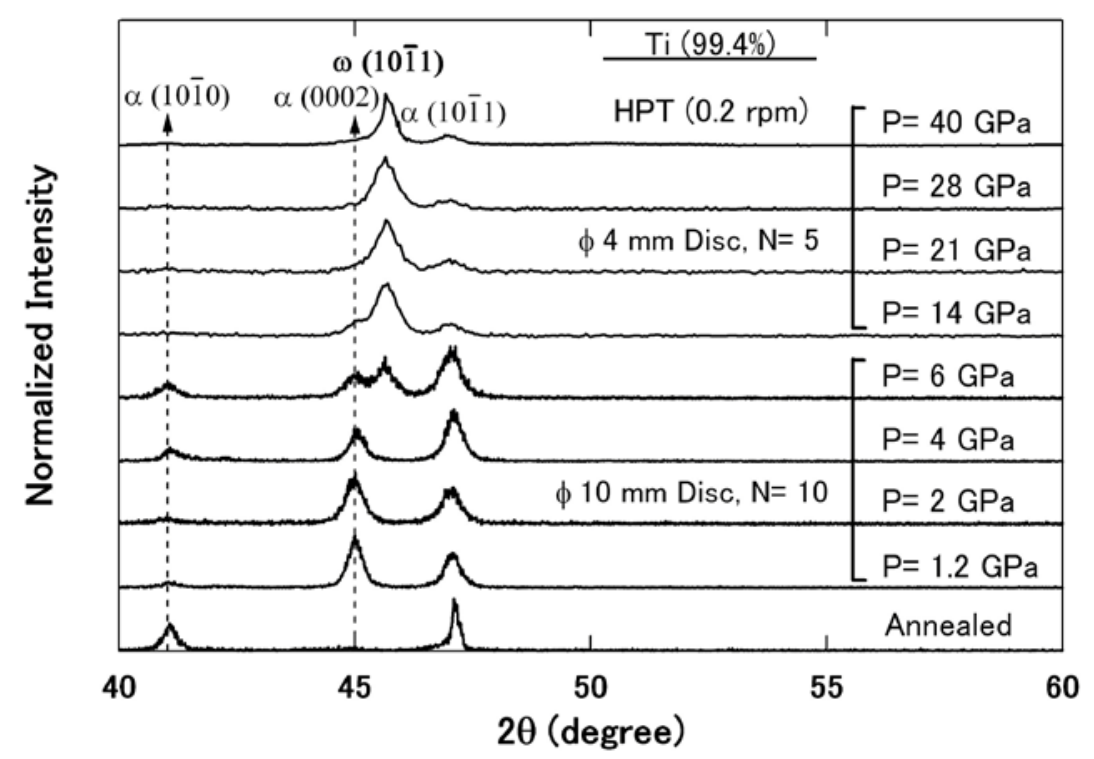

Fig. 5 X-ray diffraction pattern of Ti at saturation stage under different processing pressures.

Figure 6 delineats the stress-displacement curves obtained from bending tests at room temperature with a cross-head speed of $0.5 \mathrm{~mm} / \mathrm{s}$ for samples processed after 10 revolutions under pressures of 2 and $6 \mathrm{GPa}$ including an annealed sample before HPT. The yield strength increases significantly after HPT when compared with the annealed sample: $0.6 \mathrm{GPa}$ for the annealed but 2.0 and $1.8 \mathrm{GPa}$ for the samples after processing at 2 and $6 \mathrm{GPa}$, respectively. The elongation to failure is very large for the sample processed at $2 \mathrm{GPa}$ but it is significantly reduced for the sample processed at $6 \mathrm{GPa}$. Figure 7 demonstrates more directly the difference in the ductility by showing the appearance of specimens after manual bending. The sample processed at $2 \mathrm{GPa}$ bent to a hairpin shape confirming an excellent ductility and this is even comparable with the ductility of the annealed sample. However, the sample processed at $6 \mathrm{GPa}$ failed without any appreciable plastic deformation. It is considered that little ductility of the sample processed at $6 \mathrm{GPa}$ should be attributed to the formation of the $\omega$-phase which is known as hard but brittle [14]. 
Advanced Materials Research, Vols. 89-91 (2010), pp. 171-176

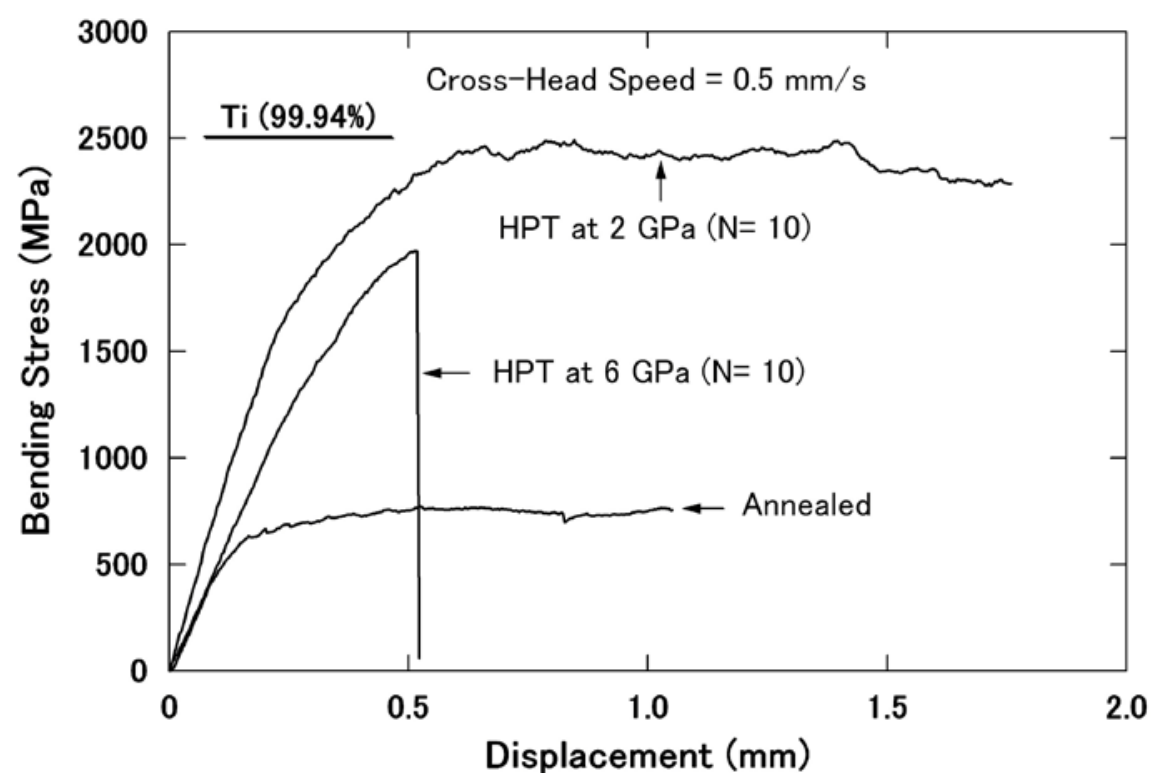

Fig. 6 Bending stress versus displacement curves obtained for annealed sample and HPT discs processed for 10 revolutions under pressures of 2 and 6 GPa.

\title{
Annealed
}

\author{
$\mathrm{HPT}$ at $2 \mathrm{GPa}$ \\ $(\mathrm{N}=10)$
}
HPT at $6 \mathrm{GPa}$
$(\mathrm{N}=10)$

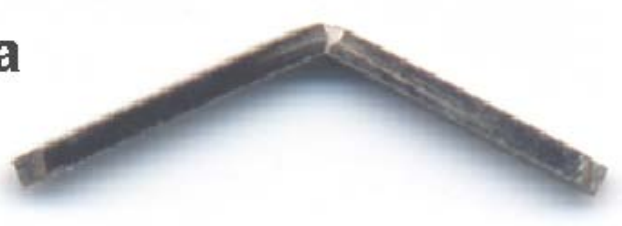

$5 \mathrm{~mm}$

Fig. 7 Appearance of bending specimens after manual bending for annealed sample and HPT discs processed for 10 revolutions under pressures of 2 and $6 \mathrm{GPa}$. 


\section{Advanced Materials Research, Vols. 89-91 (2010), pp. 171-176}

\section{Conclusions}

1. The hardness increases with imposed strain and saturates to a constant level where no change in hardness occurs with further straining.

2. The saturation hardness is almost constant for the pressures up to $4 \mathrm{GPa}$ but increases with a further increase in the pressure. XRD analysis reveals that the increase in the saturation hardness for the pressures higher than $4 \mathrm{GPa}$ is attributed to an $\alpha \rightarrow \omega$ phase transformation.

3. TEM observation shows that the microstructures at the saturation level after processing at $6 \mathrm{GPa}$ consist of grains with the average size of $\sim 150 \mathrm{~nm}$. The grains are surrounded by boundaries of high misorientations and some strain associated with dislocations is present within the grains.

4. Bending tests show that there is a remarkable increase in the yield strength after processing at 2 and $6 \mathrm{GPa}$. The elongation to failure for the sample processed at $2 \mathrm{GPa}$ is as large as the annealed sample but it is significantly reduced for the sample processed at $6 \mathrm{GPa}$.

\section{Acknowledgements}

One of the authors (KE) would like to thank the Islamic Development Bank for a scholarship. This work was supported in part by the Light Metals Educational Foundation of Japan, in part by a Grant-in-Aid for Scientific Research from the Ministry of Education, Culture, Sports, Science and Technology, Japan, in Priority Areas "Giant Straining Process for Advanced Materials Containing Ultra-High Density Lattice Defects" and in part by Kyushu University Interdisciplinary Programs in Education and Projects in Research Development (P\&P).

\section{References}

[1] V.S. Zhernakov, V.V. Latysh, V.V. Stolyarov, A.I. Zharikov and R.Z. Valiev: Scripta Mater. Vol. 44 (2001), p. 1771.

[2] R. Z. Valiev, I. P. Semenova, E. Jakushina, V.V. Latysh, H. Rack, T.C. Lowe, J. Petruzelka, L. Dluhos, D. Hrusak and J. Sochova: Mater. Sci. Forum Vol. 584-586 (2008), p. 49.

[3] A.V. Sergueeva, V.V. Stolyarov, R.V. Valiev and A.K. Mukhrjee: Scripta Mater. Vol. 45 (2001), p. 747.

[4] A. V. Sergueeva, C. Song, R. Z. Valiev and A. K. Mukherejee: Mater. Sci. Eng. A Vol. 339 (2003), p. 159.

[5] C. Rentenberger, T. Waitz, H.P. Karnthaler, Mater. Sci. Eng. A Vol. 462 (2007), p. 283.

[6] R.Z. Valiev, R.K. Islamgaliev and I.V. Alexandrov: Prog. Mater. Sci. Vol.45 (2000) p. 103.

[7] A.R. Kilmametov, A.V. Khristoforova, G. Wilde, R.Z. Valiev, Z. Kristallogr. Suppl. Vol. 26 (2007), p. 339.

[8] Todaka, J. Sasaki, T. Moto, M. Umemoto, Scripta Mater. Vol. 59 (2008), p. 615.

[9] K. Edalati, E. Matsubara and Z. Horita: submitted to Metall. Mater. Trans. A (2008).

[10] K. Edalati, T. Fujioka and Z. Horita: Mater. Trans. Vol. 50 (2009), p. 44.

[11] K. Edalati, T. Fujioka and Z. Horita, Mater. Sci. Eng. A Vol. 497 (2008), p. 168.

[12] D. Errandonea, Y. Meng, M. Somayazulu and D. Haussermann: Physica B Vol. 355 (2005), p. 116.

[13] V.A. Zilbershtein, N.P. Chistotina, A.A. Zharov, N.S. Grishina, E.I. Estrin, Fiz. Metal. Metalloved. Vol. 39 (1975), p. 445.

[14] S.K. Sikka, Y.K. Vohra and R. Chidambaram: Prog. Mater. Sci. Vol. 27 (1982), p. 245. 